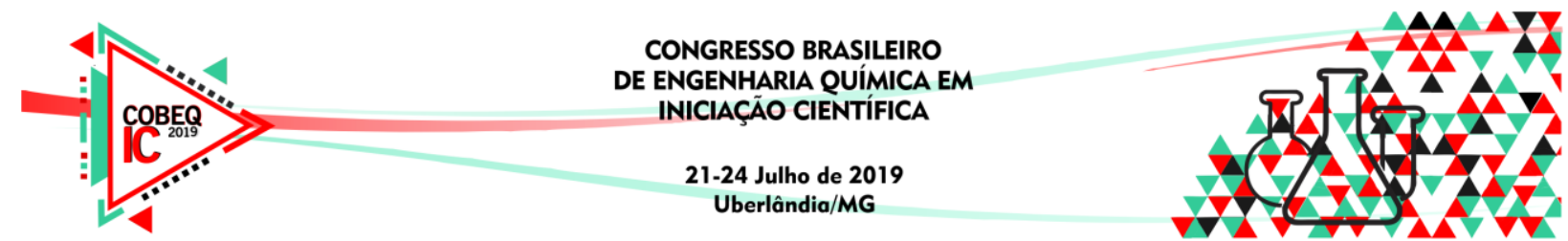

\title{
ANÁLISE DA TEMPERATURA DE CRESCIMENTO DE FUNGOS FILAMENTOSOS COLETADOS EM DISTINTAS ÁREAS DE MINAS GERAIS
}

\author{
J. CARVALHO ${ }^{1}$, G. O. MARINHO ${ }^{2}$ M. E. L. SPINOLA ${ }^{1}$ e V. M. BENASSI ${ }^{1}$
}

${ }^{1}$ Universidade Federal dos Vales de Jequitinhonha e Mucuri campus JK, Instituto de Ciência e Tecnologia.

${ }^{2}$ Universidade Federal dos Vales de Jequitinhonha e Mucuri campus JK, Programa de Pósgraduação em Biocombustíveis.

E-mail para contato: gessicaomarinho@gmail.com

\begin{abstract}
RESUMO - Bioprospecção significa explorar a biodiversidade e obter recursos genéticos para fins comerciais e desenvolvimento tecnológico. Assim, objetivouse analisar a temperatura de crescimento dos fungos filamentosos coletados de um lixão desativado na UFVJM, Diamantina, Minas Gerais. Diversas amostras foram coletadas, tais como solo, folhas em estágio de decomposição, sementes, entre outras, de distintas localidades de Minas Gerais como Janaúba, Jaíba, Diamantina, sendo isolados cerca de cem fungos. Dentre esses, determinou-se a melhor temperatura de crescimento de vinte e nove fungos isolados de um lixão desativado localizado na Universidade Federal dos Vales do Jequitinhonha e Mucuri campus JK, Diamantina, em meio de cultivo sólido contendo $4 \%(\mathrm{~m} / \mathrm{v})$ de aveia Quaker ${ }^{\circledR}$ e $2 \%(\mathrm{~m} / \mathrm{v})$ de ágar, sendo mantidos por 48 horas nas temperaturas de $30^{\circ} \mathrm{C}, 35^{\circ} \mathrm{C}, 40^{\circ} \mathrm{C}$ e $45^{\circ} \mathrm{C}$. Realizou-se, então, a medição do raio das colônias para determinar a taxa de crescimento em centímetros por hora $\left(\mathrm{cm} \cdot \mathrm{h}^{-1}\right)$. Observou-se que a maioria dos fungos em estudo apresentaram características mesofílicas, ou seja, a melhor taxa de crescimento foi entre $30^{\circ} \mathrm{C}$ e $35^{\circ} \mathrm{C}$, dos quais vinte e um cresceram melhor à $30^{\circ} \mathrm{C}$, e seis à $35^{\circ} \mathrm{C}$. Vale citar que, apenas um dos fungos analisados apresentou melhor crescimento à $40^{\circ} \mathrm{C}$, identificado como C121, caracterizando-se como fungo termofílico. Conclui-se, então, que o meio inóspito de um lixão pode apresentar variabilidade de micro-organismos.
\end{abstract}

\section{INTRODUÇÃO}

O Brasil é um país diverso apresentando uma rica biodiversidade. O trabalho de Forzza et al. (2010) documentou 40.989 espécies de algas brasileiras, plantas terrestres e fungos, dos quais 18.932 (46,2\%) são endêmicas do país. Contudo, Sobral e Stehmann (2009) afirmam que é muito difícil uma análise capaz de representar adequadamente a biodiversidade nativa como um todo.

O estudo da biodiversidade pode ser feito por meio da bioprospecção, termo que pode ser definido como: explorar a biodiversidade e obter recursos genéticos para fins comerciais e desenvolvimento tecnológico (FIRN, 2003). A obtenção de novos recursos biológicos é um aspecto relevante a ser destacado, visto que, micro-organismos apresentam a capacidade de 


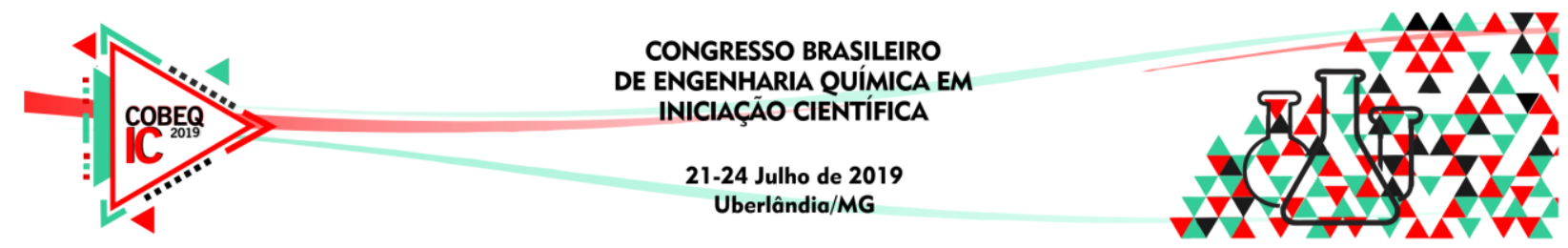

produzir compostos, podendo estes, serem aplicados em diversos processos industriais (BULL et al., 2000).

Dentre a diversidade encontrada no Brasil, destaca-se os fungos. Esses organismos podem ocupar diversos ambientes, como solo, água, ar, plantas, materiais orgânicos, dentre outros. Por isso são considerados organismos cosmopolitas, ou seja, organismos amplamente difundidos pelo mundo devido ao seu alto grau de adaptabilidade, amplitude de tolerância, e alta capacidade de dispersão. Além de sobreviverem em ambientes inóspitos, que possuem valores de $\mathrm{pH}$, temperatura, pressão e salinidade extremos (GOUKA et al., 1997).

O Reino Fungi inclui seres de dimensões consideráveis como os cogumelos e muitas formas microscópicas, como bolores e leveduras, caracterizados por serem seres eucarióticos, e, por utilizarem compostos orgânicos como fonte de carbono e energia, são denominados quimioheterotróficos.

A necessidade de uma indústria mais limpa, com responsabilidade ambiental exige que muitos dos seus processos sejam substituídos por processos biocatalíticos, utilizando microorganismos e seus bioprodutos (ACHARYA; CHAUDHARY, 2012). Assim, a busca por espécies fúngicas tem sido um importante aliado para a descoberta de novos metabólitos.

A diversidade metabólica e o crescimento rápido desses micro-organismos, permite que eles sejam cultivados em meios de cultura relativamente simples, de fácil manuseio e com condições de cultivo facilmente controladas, além de ocupar pouco espaço (TREVISAN, 2004). Tornando o seu uso um processo mais viável para aplicação industrial (BETINI et al., 2008).

Os metabólitos secretados por micro-organismos possuem múltiplas finalidades, tais como compostos antimicrobianos (SOBRAL et al. 2017), exopolissacarídeos (FREITAS; TORRES, REIS, 2017), amilases com alta estabilidade e especificidade (SINDHU, 2017; HOMAEI, 2016), celulases, xilanases e proteases oriundas de linhagens fúngicas (CUNHA et al., 2016), entre muitos outros.

A temperatura é um dos fatores ambientais que mais condiciona o crescimento de organismos vivos nos sistemas de cultivo empregados em laboratório (AZEVEDO, 2018). Os fungos que toleram temperaturas mais elevadas são de grande interesse devido ao seu potencial de produzir metabólitos tolerantes ao calor, característica altamente empregada nos processos biotecnológicos. Tal fator está baseado no fato de que a atividade ótima dos metabólitos microbianas se relacionam com as condições de temperatura ótima em que ocorre o crescimento máximo dos micro-organismos (OLIVEIRA et al., 2015).

A capacidade dos micro-organismos de crescerem e produzirem metabólitos influenciada pela temperatura indica sua tolerância ao calor gerado durante a fermentação do estado sólido. Pode-se observar que a elevação da temperatura de reação geralmente aumenta a taxa de reação e reduz o risco de contaminação microbiana (NAVES et al.,2010; TRAKARNPAIBOON, et al., 2017). Esta variável aumenta o interesse de obtenção de microorganismos capazes de se desenvolverem em diversas temperaturas, para tanto o estudo de termofilia apresenta-se como relevante.

Diante disso, o presente trabalho objetivou analisar a temperatura de crescimento de vinte e nove fungos filamentosos isolados no lixão desativado da Universidade Federal dos Vales do Jequitinhonha e Mucuri campus JK, Diamantina, Minas Gerais. 


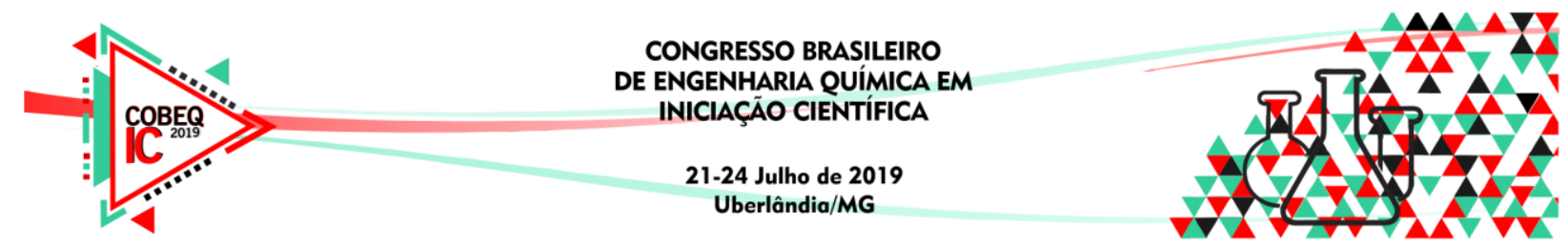

\section{METODOLOGIA}

Para determinar a melhor temperatura de crescimento dos fungos filamentosos selecionados foi utilizado o meio de cultivo Emerson (1941), constituído com $4 \%$ (m/v) de farinha de aveia Quaker ${ }^{\circledR}$ e $2 \%(\mathrm{~m} / \mathrm{v})$ de ágar. Para cada isolado procedeu-se o repique pontual em placas de Petri, contendo $10 \mathrm{~mL}$ de meio de cultivo, previamente autoclavados, sendo mantidos nas temperaturas de $30^{\circ} \mathrm{C}, 35^{\circ} \mathrm{C}, 40^{\circ} \mathrm{C}$ e $45^{\circ} \mathrm{C}$, em estufa bacteriológica. Após 48 horas de cultivo, realizou-se a medição do raio das colônias para quantificar a taxa de crescimento das hifas em centímetros por hora $\left(\mathrm{cm} \cdot \mathrm{h}^{-1}\right)$ (Figura 1).

Figura 1- Determinação do raio de crescimento fúngico para análise da taxa de crescimento em centímetros por hora.

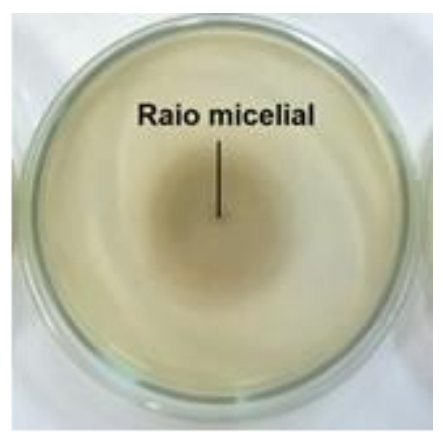

Os resultados obtidos foram analisados e os organismos foram classificados de acordo com a sua melhor temperatura de crescimento, sendo determinado $30^{\circ} \mathrm{C}-35^{\circ} \mathrm{C}$ para fungos mesófilos, e acima de $40^{\circ} \mathrm{C}$ para fungos termofílicos (MAHESHWARI et al., 2000; OLIVEIRA, 2005).

\section{RESULTADOS}

Observou-se que a maioria dos fungos em estudo apresentam características mesofílicas, ou seja, apresentaram melhor taxa de crescimento em temperaturas médias entre $30^{\circ} \mathrm{C}$ e $35^{\circ} \mathrm{C}$. Entre esses, vinte e um cresceram melhor à $30^{\circ} \mathrm{C}$, e seis à $35^{\circ} \mathrm{C}$, sendo que apenas um dos fungos analisados apresentou melhor crescimento à $40^{\circ} \mathrm{C}$, caracterizando-se como fungo termofílico. Entretanto, ele não apresentou crescimento à $50^{\circ} \mathrm{C}$ (Tabela 1).

O efeito da temperatura no crescimento dos fungos é de extrema importância, pois possibilita caracterizar a temperatura ótima de crescimento dos micro-organismos, além disso, conhecer o quanto os fungos podem crescer frente à variação de temperatura permite diferenciar os estados de crescimento e de sobrevivência dos organismos, uma vez que a temperatura é um fator crucial no desenvolvimento dos mesmos (MADAN; THIND, 1998).

A temperatura ótima de crescimento é a temperatura na qual a espécie apresenta seu melhor potencial de crescimento, geralmente os psicrófilos crescem melhor nas temperaturas de $0^{\circ} \mathrm{C}$ à $15^{\circ} \mathrm{C}$, os mesófilos nas temperaturas de $25^{\circ} \mathrm{C}$ à $35^{\circ} \mathrm{C}$ e os termofílicos de $50^{\circ} \mathrm{C}$ à $60^{\circ} \mathrm{C}$ (TORTORA; FUNKE; CASE, 2012). 


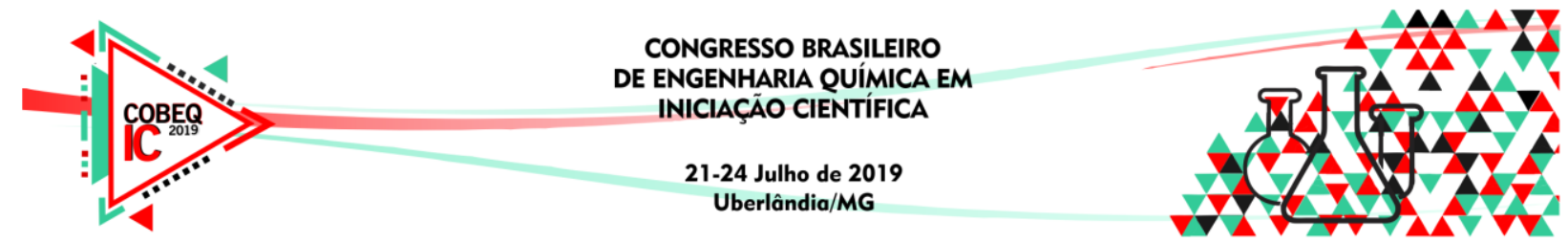

Tabela 1- Taxa de crescimento dos fungos filamentosos cultivados em diferentes temperaturas.

\begin{tabular}{|c|c|c|c|}
\hline \multirow[t]{2}{*}{ FUNGOS } & \multicolumn{3}{|c|}{$\begin{array}{l}\text { Temperaturas de crescimento } \\
(\mathrm{cm} / \mathrm{h})\end{array}$} \\
\hline & $30^{\circ} \mathrm{C}$ & $35^{\circ} \mathrm{C}$ & $40^{\circ} \mathrm{C}$ \\
\hline C121 & 0,262 & 0,3 & 0,349 \\
\hline C122 & 0,12 & 0,01 & - \\
\hline C221 & 0 & 0,3 & 0,4 \\
\hline C222 & 0,1 & 0,069 & - \\
\hline C321 & 0,113 & 0,02 & - \\
\hline C322 & 0,111 & 0,01 & - \\
\hline C331 & 0,13 & 0,1 & - \\
\hline C332 & $\mathbf{0 , 0 1}$ & - & - \\
\hline C333 & 0,014 & 0,012 & - \\
\hline C421 & 0,055 & 0,062 & 0,055 \\
\hline $\mathrm{C} 423$ & $\mathbf{0 , 0 7 7}$ & - & - \\
\hline C432 & 0,2 & 0,3 & 0,01 \\
\hline $\mathrm{C} 433$ & 0,01 & - & - \\
\hline C434 & 0,012 & 0,04 & - \\
\hline C435 & $\mathbf{0 , 0 2 7}$ & - & - \\
\hline $\mathrm{C} 441$ & 0,03 & 0,14 & 0,05 \\
\hline I 1.2.1 & 0,157 & $\mathbf{0 , 1 7}$ & 0,12 \\
\hline I 2.2 .1 & 0,054 & 0,04 & - \\
\hline I 2.2 .3 & 0,17 & 0,2 & 0.13 \\
\hline I 2.3 .1 & $\mathbf{0 , 0 2 3}$ & - & - \\
\hline I 2.3 .4 & 0,025 & - & - \\
\hline I 2.3 .5 & 0,016 & - & - \\
\hline I 3.2 .1 & 0,55 & 0,02 & - \\
\hline I 3.2 .2 & 0,23 & - & - \\
\hline I 3.2 .3 & 0,024 & - & - \\
\hline I 4.3.1 & 0,05 & 0,04 & - \\
\hline I 4.3 .2 & 0,023 & - & - \\
\hline I 4.4 .1 & 0,058 & 0,04 & - \\
\hline I 4.4 .3 & $\mathbf{0 , 0 2 3}$ & - & - \\
\hline
\end{tabular}




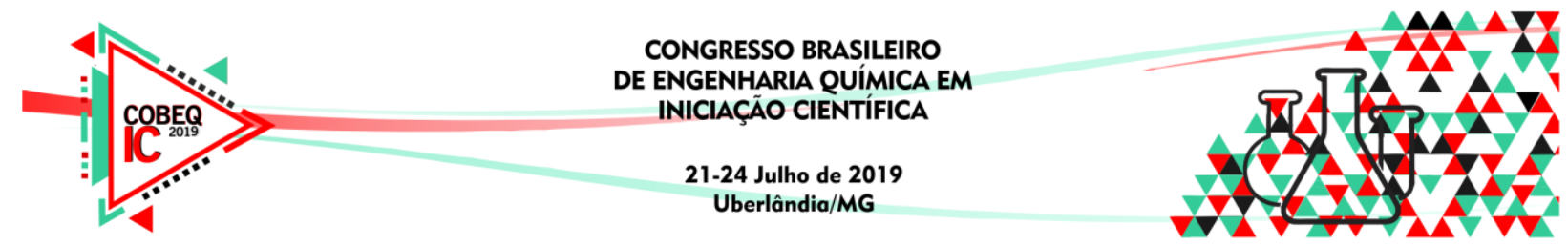

Tais resultados podem estar interligados ao ambiente de origem desses organismos. De acordo com Salar e Aneja (2007), a temperatura, umidade e atmosfera do ambiente de origem dos fungos são os principais substratos para o seu desenvolvimento. Eles foram retirados de áreas abertas de um lixão, ou seja, em contanto com a temperatura ambiente. E em uma cidade que apresenta clima ameno, com temperaturas em torno de $15^{\circ} \mathrm{C}-30^{\circ} \mathrm{C}$.

Observou-se, também, que alguns fungos como os identificados como C221 e C332 cresceram apenas à $30^{\circ} \mathrm{C}$ com uma baixa taxa de crescimento. Isso pode ter ocorrido como consequência do meio de cultura utilizado. O meio de aveia é rico em diferentes nutrientes, podendo provocar o crescimento de diversos organismo, porém, cada fungo apresenta exigências metabólicas diferentes, podendo ter o seu crescimento ativado ou inibido de acordo com o meio a ele oferecido.

\section{CONCLUSÕES}

A Bioprospecção de fungos isolados é uma alternativa viável que permite explorar o potencial biotecnológico de determinada região, possibilitando o conhecimento das espécies de microrganismos produtores de metabólitos com interesse biotecnológico. Assim, o seguinte trabalho concluiu que os fungos analisados apresentam melhor crescimento em temperaturas de acordo com a sua região de origem. Eles cresceram em temperaturas de 30 ${ }^{\circ} \mathrm{C}-35{ }^{\circ} \mathrm{C}$, sendo caracterizados como mesofílicos.

\section{REFERÊNCIAS}

MAHESHWARI R, BHARADWAJ G, BHAT MK. Thermophilic fungi: their physiology and enzymes. Microbiol Mol Biol Rev 64(3):461-488, 2010.

SALAR TK, ANEJA KR. Thermophilic fungi: taxonomy and biogeography. J Agric Technol 3(1):77-107, 2007.

EMERSON, R. An experimental study of the life cycles and taxonomy of Allomyces. Lloydia, v. 4, p. 77-144, 1941.

TORTORA, Gerard J.; CASE, Christine L.; FUNKE, Berdell R. Microbiologia-12a Edição. Artmed Editora, 2016.

SOBRAL, LAUREANA V. et al. Antimicrobial and enzymatic activity of anemophilous fungi of a public university in Brazil. An. Acad. Bras. Ciênc., v.89, n.3, pp.2327-2340, 2017.

ACHARYA, S.; CHAUDHARY, N. Bioprospecting thermophiles for cellulase production: a review. Brazilian Journal of Microbiology, São Paulo, v.43, n.3, p. 844-856, 2012.

AZEVEDO, L. V. O potencial de Streptomyces isolados na região de maués na produção de enzimas hidrolíticas. Ciência e Natura, Santa Maria v.39, n.2, p. 202 - 210, 2018.

BETINI, G. F.; PLATAS, G.; FILLOLA, A.; JIMENEZ, M.R.; COLLADO, J.; VICENTE, F.; MARTIN, J.; GONZALEZ, A.; BUR-ZIMMERMANN, J.; TORMO J. R.; PELAEZ, F. Enhancement of antibiotic and secondary metabolite detection from filamentous fungi by growth on nutritional arrays. Journal of Applied Microbiology, Oxford, v. 104, n. 6, p. 1644-1658, 2008. 


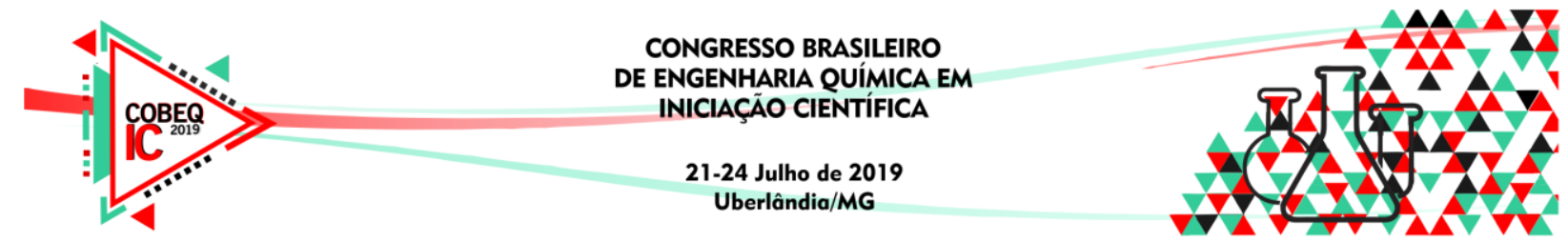

BULL, A. T.; WARD, A. C.; GOODFELLOW, M. Search and Discovery Strategies for Biotechnology: the Paradigm Shift. Microbiology and Molecular Biology Reviews, Nova Iorque, v. 46, n. 3, p. 573-606, 2000.

FIRN, R.D. Bioprospecting-Why is it so unrewarding? Biodiversity and Conservation, Londres, v. 12, n. 2, p. 207-216, 2003.

FREITAS; TORRES, REIS. Produção e caracterização parcial de $\alpha$ - amylase de Syncephalastrum racemosum. Revista Brasileira de Biociências, v. 26, p.266- 232, 2017.

GOUKA, R. J.; PUNT, P. J.; VAN DEN HONDEL, C. A. M. J. J. Efficient production of secreted proteins by Aspergillus: progress, limitations and prospects. Appl Microbiol Biotechnol, v. 47, p. 1-11, 1997.

HOMAEI, P.; HARMAN, G. E. Trichoderma species-opportunistic, avirulent plant symbionts.Nature Reviews Microbiology,London, v. 2, n. 1 , jan 2016.

MADAN, M.; THIND, K. S. Physiology of Fungi. New Delhi: A. P. H. Publishing Corporation, 1998.

NAVES, R. F.. Contaminação microbiana nas etapas do processamento e sua influência no rendimento fermentativo em usinas alcooleiras. Enciclopédia Biosfera, Centro Científico Conhecer-Goiânia, v. 6, n. 11, p. 1-16, 2010.

OLIVEIRA, T. B.; GOMES, E.; RODRIGUES, A.; Thermophilic fungi in the new age of fungal taxonomy. Extremophiles, v. 19, n. 1, p. 31-37, 2015.

LIVEIRA, M. M. D. et al. Isotermas de sorção do resíduo agroindustrial de casca do abacaxi (Ananas comosus L. Mer). Revista Brasileira de Engenharia Agrícola e Ambiental, Campina Grande, v. 9, n. 4, p. 565-569, 2005.SINDHU, 2017;

TRAKARNPAIBOON, Srisakul et al. Enhanced production of raw starch degrading enzyme using agro-industrial waste mixtures by thermotolerant Rhizopus microsporus for raw cassava chip saccharification in ethanol production. Preparative Biochemistry and Biotechnology, v. 47, n. 8, p. 813-823, 2017.

TREVISAN, H. C. "Lipases". In: SAID, S. \& PIETRO, R. C. L. R. Enzimas como agente Biotecnológico. 1. ed. Ribeirão Preto: Editora Legis Summa, 2004.

FORZZA RC, et al. Catálogo das Plantas e Fungos do Brasil, 2 vols. Andrea Jakobsson Estúdio and Rio de Janeiro Botanical Garden, 2010.

SOBRAL M, STEHMANN JR. An analysis of new angiosperm species discoveries in Brazil (1990-2006). Taxon 58: 227-232, 2009. 